\title{
A surprising palmar nevus: A case report
}

\section{Rana Rafiei ${ }^{1}$, Seyyedezeinab Azimi ${ }^{2}$, Alireza Sheibani ${ }^{2}$, Behnam Rafiee $^{3}$, Sara Najirad ${ }^{4}$}

${ }^{1}$ Fellow Ship of Dermatopathology, Skin Research Center, Guilan University of Medical Sciences, Razi Hospital, SardareJangal Street, Rasht, Iran, ${ }^{2}$ Skin Research Center, Guilan University of Medical Sciences, Razi Hospital, SardareJangal Street, Rasht, Iran, ${ }^{3}$ Department of Pathology, NYU Winthrop Hospital, New York, USA, ${ }^{4}$ Nassau University Medical Center, Department of Internal Medicine, 2201 Hempstead turnpike, East Meadow, NY, USA

Corresponding author: Rana Rafiei, MD., E-mail: rafieirana2@gmail.com

\begin{abstract}
Raised palmar or plantar nevus especially in white people is an unusual feature. We present an uncommon palmar compound nevus in a 26-year-old woman with a large diameter $(6 \mathrm{~mm})$ which had a collaret-shaped margin. In histopathologic evaluation intralymphatic protrusions of nevic nests were noted. This case was surprising to us for these reasons: size, shape, location and histopathology of the lesion. Palmar nevi are usually junctional (flat) and below $3 \mathrm{~mm}$ diameter and intra lymphatic protrusion or invasion in nevi is an extremely rare phenomenon.
\end{abstract}

Key words: Palmar; Nevus; Intralymphatic

\section{INTRODUCTION}

Plantar nevi are more prevalent than palmar nevi especially in dark skin subjects. The raised nevi are more common on plantar surface [1]. Kopf reported that $9 \%$ of people had a pigmented lesion on the sole and $5.8 \%$ of subjects had a pigmented lesion on the palms with equal frequency in both sexes [2] but Gary, et al. mentioned that acral nevi were more prevalent in women with light skin subjects [1].

\section{CASE REPORT}

We present herein a 26-year-old woman with Fitzpatrick phototype IV with a dome-shaped nodule with a collaret-shaped margin on her right palmar area from childhood which had about $6 \mathrm{~mm}$ diameter. Focal linear blue-gray pigmentations were seen on the surface (Fig. 1). She complained of a vague pain on the lesion during hand-working or palpation. She mentioned pigmentation of the lesion was more prominent during childhood and then gradually decreased. She had no history of trauma or foreign body inoculation.
In physical examination direction of skin lines were quite different on the lesion compared to adjacent skin and separated from it by a collaret. She also had a pigmented macule with 3 millimeter diameter near this lesion. There were two junctional nevi on her trunk too.

Skin biopsy of the palmar lesion was made with differential diagnoses of adnexal tumors, traumatic neuroma and foreign body granuloma. Histopathologic studies confirmed focal lentiginous proliferation of melanocytes at dermo-epithelial junction associated with circumscribed and symmetrical mass of melanocytic component which consisted of dermal nevic nests that showed expected maturation of blandlooking nevic cells with dermal fibroplasia. Eccrine duct and neural fibers were entrapped by nevic cells. In superficial part of the lesion intralymphatic protrusions of nevic nests were noted which were confirmed by immunohistochemistry study (Figs. 2 and 3).

Unfortunately dermatoscopy of the lesion was not done before skin biopsy. 


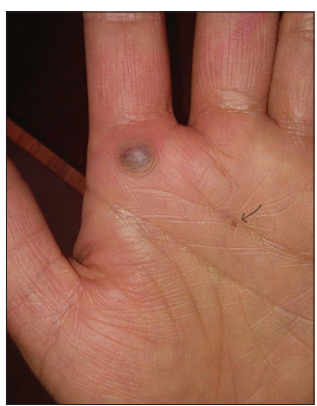

Figure 1: A pigmented dome-shaped nodule is seen on the palmar surface; also a tiny pigmented macule is pointed by an arrow.

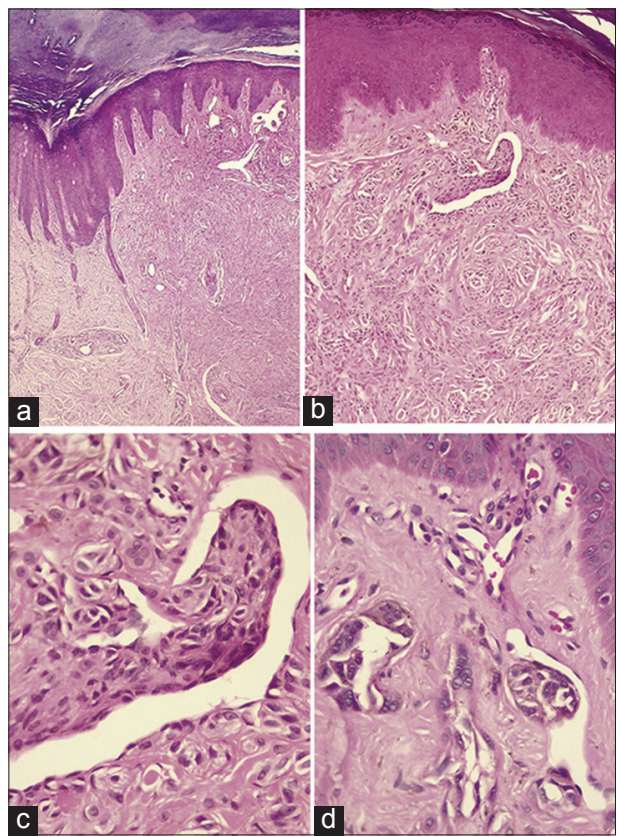

Figure 2: (a) Dermal mass of melanocytic components which consist of nevic nests with dermal fibroplasia and entrapment of eccrine duct and neural fibers by nevic cells. (b-d) In superficial part of this lesion intralymphatic protrusions of nevic nests are noted. (H \& E, original magnification a: x40, b: x100, c, d: x400).
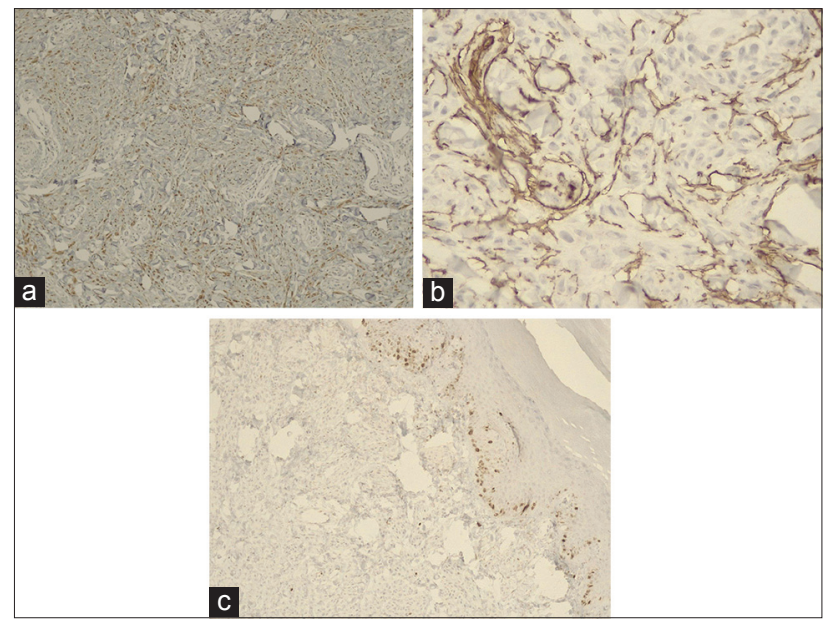

Figure 3: Immunohistochemistry evaluations show: (a) Melanocytic nesting (HMB45 staining), (b) lymphatic channel formations (CD31 staining) and c) low mitotic rate of the nevic cells (Ki67 staining) in favor of a benign melanocytic lesion.

\section{DISCUSSION}

Palmar and plantar melanocytic nevi are more common in dark skin patients, women, age younger than 50 years and in subjects who have more atypical nevi. The greatest diameter of palmar nevi in white subjects has been $0.5-3 \mathrm{~mm}$ and only $3 \%$ of palmar nevi are raised. They usually have light brown pigmentation. Plantar nevi are more common than palmar nevi and usually have compound nevic features [1]. Size, dome-shaped feature with a collaret view, low pigmentation and pain of the lesion in our case, prompted us not to think initially about palmar nevus.

Acral melanocytic nevus may have special histopathologic findings which are different from other areas. These unusual findings include single pagetoid spread of melanocytes without atypia, pigmentation of cornified layer, syringotropism, lymphocytic inflammation and dermal fibroplasia which might be misdiagnosed as melanoma but melanoma is characterized by high number of atypical cells and mitotic figures [3].

Intralymphatic protrusion or lymphatic invasion of nevic cells is a rare incidental event which probably could be better seen with more tissue sections [4]. This phenomenon has been reported in 2.7\%- 6.5\% of nevi which might be under-diagnosed because of focal manifestation. Pseudolymphatic spaces in nevic structures are usually characterized by papillary projections in dermal nevi which are covered by cuboidal nevic cells instead of flattened endothelial cells, so they should be differentiated from true lymphatic spaces. Leblebici, et al. reported lymphatic invasion of nevic cells in 10 out of 369 cases with nevi. These 10 cases aged 7 to 33 years and they had compound or intradermal nevus. Lower detection of lymphatic invasion in nevi should be considered due to limited sections and rapid diagnosis for nevus samples. Intralymphatic nevic aggregates might be lost during tissue processing for immunohistochemical study [5] Up to now this phenomenon has no prognostic significance and could be explained by shifting of nevic cells resulted from mechanical forces toward lymphatic spaces [4].

In conclusion our case had a benign compound nevus on the palmar surface which clinically and histopathologically surprised us. 


\section{REFERENCES}

1. Palicka GA, Rhodes AR. Acral melanocytic nevi: prevalence and distribution of gross morphologic features in white and black adults. Arch Dermatol. 2010;146:1085-94.

2. Boyd AS, Rapini RP. Acral melanocytic neoplasms: a histologic analysis of 158 lesions. J Am Acad Dermatol. 1994;31:740-5.

3. Hosler GA, Moresi JM, Barrett TL. Nevi with site-related atypia: a review of melanocytic nevi with atypical histologic features based on anatomic site. J Cut Pathol. 2008;35:889-98.

4. Kim HS, Lee SH, Moon HS, Kim YW. Intradermal melanocytic nevus with lymphatic nevus cell embolus: A case report. Oncol Letters. 2014;7:331-3.

5. Leblebici C, Kelten C, Gurel MS, Hacihasasanoglu E. Intralymphatic nevus cells in benign nevi. Ann Diag Pathol. 2016;25:1-6.

Copyright by Rana Rafiei, et al. This is an open-access article distributed under the terms of the Creative Commons Attribution License, which permits unrestricted use, distribution, and reproduction in any medium, provided the original author and source are credited.

Source of Support: Nil, Conflict of Interest: None declared. 